\title{
Local Engagement with the Election Administration and Voting Survey (EAVS)
}

\author{
Susan Gill
}

Abstract The introduction of new data collection tools in election administration can create unique challenges for local election officials. This case presents one local election official's experience with the Election Administration and Voting Survey (EAVS) from its inception following the passage of the Help America Vote Act (HAVA) in 2002; also discussed is the important role that vendors play in ensuring that local jurisdictions provide the type of data required by the EAVS and other election administration data collection tools.

Keywords Election Administration and Voting Survey (EAVS) - Data

- Vendors

My name is Susan Gill and I have been the Citrus County, Florida, Supervisor of Elections for 23 years. I have served as President of the Florida State Association of Supervisors of Elections and have chaired and served on many committees. I am currently serving as Chair of the Election

S. Gill $(\bowtie)$

Citrus County Elections, Inverness, FL, USA

e-mail: Susan.Gill@votecitrus.com

(C) The Author(s) 2019

M. Brown et al. (eds.), The Future of Election Administration, Elections, Voting, Technology, https://doi.org/10.1007/978-3-030-18541-1_30 
Center (National Association of Election Officials) Board of Directors. I am the Co-Chair of the Vote Center Task Force for our State Association.

Citrus County, Florida, is a west central coastal county located approximately 1.5 hours north of Tampa and 1.5 hours west of Orlando. The population is 145,000 of which approximately 109,000 are registered voters. We are largely a retirement community comprising people who have moved to Florida from many different states. In presidential elections, $86 \%$ of the voters 61 years of age and older turn out to vote. The county has a small minority population. A federal court order requires ballots and all election related materials be printed in the Spanish language starting March 2020. The Citrus County Supervisor of Elections has nine fulltime employees.

The availability of data down to the granular level through computer software programs has enabled election professionals to make more informed decisions. For example, we are able to make changes in the allocation of resources by analyzing the post-election data on when and where voters are voting. Florida law allows no excuse vote by mail, early voting, or Election Day voting at the polls, and so these differences really matter.

Analyzing the post-election data showed us that more voters were choosing to vote by mail and early vote. As a result, in 2012 we reduced the number of polling places by ten to adjust to the higher number of voters that we expected to vote prior to Election Day. Our State Vote Center Committee continues to study the numbers and methods of voting to see if our State is ready, willing, and able to move on to Vote Centers, which will require a legislative change.

Data are available real time on the numbers of voters voting at the early vote sites and at the polls on Election Day. The number of vote by mail ballots is available as the signatures are matched on the registration system. On our website, voters are able to find out the status of their vote by mail ballot: when it was mailed and when the voted ballot was received in our office.

The Help America Vote Act (HAVA) requires the Election Assistance Commission (EAC) to gather information from all the jurisdictions receiving federal funds for accountability purposes. Another survey! We had no idea what information would be asked in the survey and what data they would be requesting. We knew this was no ordinary survey. We would be required to complete the Election Administration and Voting Survey (EAVS) survey and the State Division of Elections would be responsible for making sure that all counties complied. 
When the Election Administration and Voting Survey arrived we were so frustrated. We felt like crying! While some of the questions such as requests for registration numbers were straightforward, others in the vote by mail section were more confusing. The staff, our Operations Manager, the Vote by Mail Coordinator, and the Registration Administrator along with myself were all involved with gathering this information. We would look at a question and each staff member would have a different understanding and a different interpretation of what was being asked.

In addition, the Federal Voting Assistance Program (FVAP) had another survey that asked the same questions in a different way, which produced a different answer that, of course, did not match the EAVS answer to the similar question. We did not think the surveys were an effective tool.

Life is better now. The EAC has continually tried to improve the survey and make it more user-friendly. The FVAP survey questions are now included in the survey. We receive a copy of the survey ahead of time which helps us keep on top of gathering the data that will be required on the survey. VR Systems, Inc., our voter registration vendor, has also helped design the registration software to make it easier for us to access the data the way the EAVS survey requests it.

The usability of the EAVS Report is also better now. There are still areas needing improvement. To address these, the EAC and the survey developers have reached out to election officials to listen to our suggestions. One issue we have is that after the survey has been completed online, there is no way to print a copy for reference. We only have our handwritten worksheet. This is important because our office and the state office receive public records requests asking for the same information and we would like a copy of the final survey for reference.

A second issue has to do with the due date of the EAVS. The due date for the 2016 EAVS was February 2, 2017. We would like the completion date for the survey to be the end of December of the election year. This will allow us to start the new year having completed all the necessary paperwork from the previous year's election. Lastly, the information provided to complete the EAVS is not always helpful. For the 2016 survey, we were provided additional information which was not provided in the past, and some of which was redundant. Materials included A Guide to Election Administration and Voting Survey, Statutory Overview, Guide to Using the 2016 Election Administration and Voting Survey Data Templates, and the Template. Our vendor, VR Systems, Inc., was a great help in setting up their programs to easily provide the data requested. VR Systems, Inc., also used the Suggested Guidelines for Completion of the US Election Assistance Commission 2016 Election Administration \& Voting Survey. 
The EAVS is mandated by the Help American Vote Act and serves as an accountability document for Congress to review. EAVS is probably most useful to those doing research wanting to study a large segment of the national election community. For an elections official making decisions specific to our own county, much of the data we need is available through our software and elections systems. However, we do keep our EAVS data at hand for Public Records Requests and other surveys. We appreciate the continuing effort to make EAVS easier to complete. We now know better what to expect and our vendor assists with providing the data in a format as requested by the EAVS. We are constantly examining our data to evaluate the need for changes in allocation of ballots, equipment, poll workers and making decisions for the future. The State collects data from all 67 counties and makes it readily available for comparison purposes.

Data collection has come a long way during the time that I have been Supervisor of Elections. The EAVS and its improvements help illustrate how trends are changing. This type of data is essential for election officials making election administration decisions. As we become more familiar with the data that we have on hand, we will be able to improve election administration even further.

Open Access This chapter is licensed under the terms of the Creative Commons Attribution 4.0 International License (http://creativecommons.org/licenses/ by $/ 4.0 /$ ), which permits use, sharing, adaptation, distribution and reproduction in any medium or format, as long as you give appropriate credit to the original author(s) and the source, provide a link to the Creative Commons licence and indicate if changes were made.

The images or other third party material in this chapter are included in the chapter's Creative Commons licence, unless indicated otherwise in a credit line to the material. If material is not included in the chapter's Creative Commons licence and your intended use is not permitted by statutory regulation or exceeds the permitted use, you will need to obtain permission directly from the copyright holder.

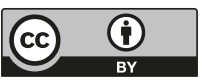

